\title{
Changing tramadol by intravenous perfusion of lidocaine + ketamine for postoperative pain management in laparoscopic colorectal surgery. Did it decrease the incidence of postoperative nausea, vomit and lleus?
}

\section{Sadurni M, Corcoy M, Rueda M, Castelltort L, Bande D, Montes A.} Hospital del Mar. Barcelona.

\section{Background and goal of study:}

Enhanced recovery after surgery guidelines recommend the use of multimodal strategies with paracetamol and NSAIDs for management of postoperative pain in laparoscopic colorectal surgery (CRS).

Opioid based therapies provide better analgesia but they may increase the incidence of postoperative nausea and vomit (PONV) or ileus. Other drugs as intravenous lidocaine and ketamine may be added at these therapies.

The goal of the study was to audit if the change of a weak opioid like intravenous tramadol by intravenous lidocaine + ketamine perfusion decreased the incidence of PONV and ileus without increasing postoperative pain in laparoscopic CRS.

\section{Materials and methods:}

We performed an audit where we compared 2 cohorts of different postoperative analgesia therapies in patients scheduled to laparoscopic oncologic colorectal surgery:

$\rightarrow$ LidoKeta Group: 2016 therapy based on a lidocaine $(1 \mathrm{mg} / \mathrm{Kg} / \mathrm{h})+$ ketamine $(0,07 \mathrm{mg} / \mathrm{Kg} / \mathrm{h})$ infusion + paracetamol $(1 \mathrm{~g} / 6 \mathrm{~h})+$ dexketoprophen (50mg/8h).

$\rightarrow$ Tramadol Group: 2015 therapy based on a tramadol $(1 \mathrm{mg} / \mathrm{Kg} / 8 \mathrm{~h})+$ paracetamol $(1 \mathrm{~g} / 6 \mathrm{~h})+$ dexketoprophen $(50 \mathrm{mg} / 8 \mathrm{~h})$.

Both strategies were administered intravenously for the first $24 \mathrm{~h}$ postoperative.

We collected demographic and intraoperative data (age, gender, BMI, ASA status and type of surgery). See Table1.

We compared the incidence of PONV (yes/no) and ileus (yes/no). See Figure 1 and Figure 2

We also analyzed pain at movement and at rest referred by the patient at 24 hours postoperative. Pain was assessed with a numeric scale (0-10). See Figure 3.

This data was obtained from a prospective collected database.

Statistical analysis: We compared PONV and ileus with a Fisher test and movement and rest pain with a student $t$ test.

\section{Results and discussion:}

We analyzed 121 patients (TPD Group=58 and LKPD Group=63). No differences found between the two groups regarding demographic and intraoperative data..

\begin{tabular}{|l|c|c|}
\hline & Tramadol Group & LidoKeta Group \\
\hline Gender (Male/Female) & $52 \% / 48 \%$ & $57 \% / 43 \%$ \\
\hline Age (Mean \pm st dev) & $71 \pm 12$ years & $68 \pm 10$ years \\
\hline IMC (Mean \pm st dev) & $27 \pm 5$ & $28 \pm 5$ \\
\hline ASA ( II / III) & $67 \% / 33 \%$ & $70 \% / 30 \%$ \\
\hline Type of Surgery: & & \\
$-\quad$ R. Hemicolectomy & $48 \%$ & $43 \%$ \\
$-\quad$ Sigmoidectomy & $24 \%$ & $38 \%$ \\
$-\quad \quad$ Rectal Resection & $28 \%$ & $19 \%$ \\
\hline
\end{tabular}

Table 1: Demographic and Intraoperative Data

Figure1: Nausea and vomiting. Day1 postoperative.

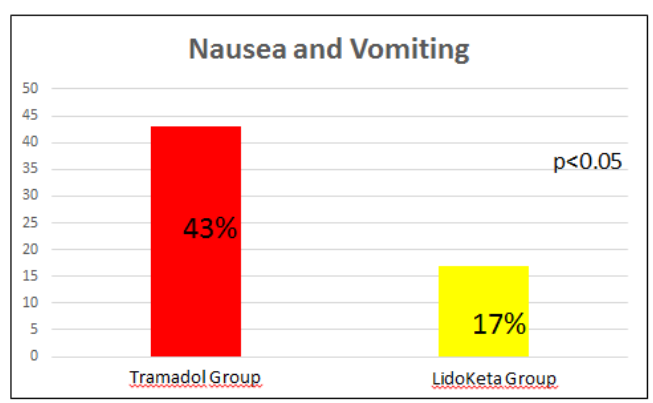

Figure2: Postoperative lleus.

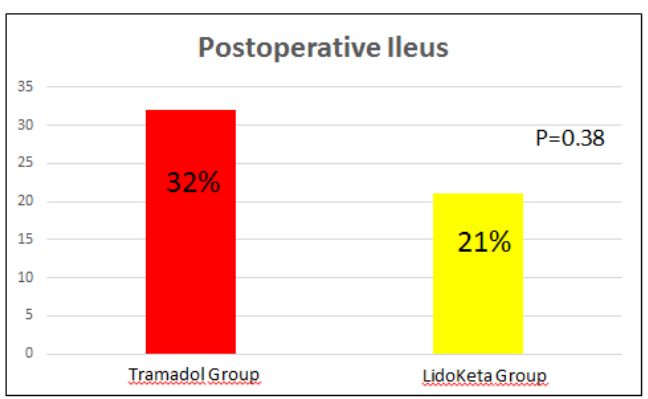

Figure3: Postoperative Pain. Day1 Postoperative.

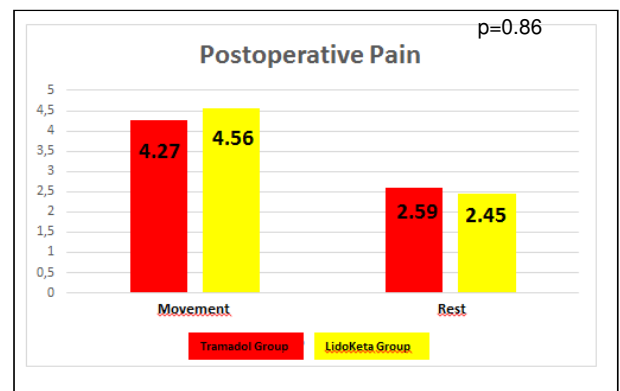

\section{Conclusion:}

- Using intravenous lidocaine + ketamine instead of tramadol decreases the incidence of PONV without worsening pain control.

- A lower incidence of postoperative ileus is seen in LidoKeta group without reaching statistical differences. 